\title{
Urbanization, agricultural water use, and regional and national crop production in China
}

\author{
Tingting Yan ${ }^{\mathrm{a}, \mathrm{b}}$, Jinxia Wang ${ }^{\mathrm{a}, *}$, Jikun Huang ${ }^{\mathrm{a}}$ \\ a Center for Chinese Agricultural Policy, Institute of Geographic Sciences and Natural Resources Research, Chinese Academy of Sciences, Jia, No. 11, \\ Datun Rd, Anwai, Beijing 100101, China \\ ${ }^{\mathrm{b}}$ University of Chinese Academy of Sciences, Beijing 100049, China
}

\section{A R T I C L E I N F O}

\section{Article history:}

Available online 12 January 2015

\section{Keywords:}

Urbanization

Agricultural water use

Crop areas

Crop production

Regional and national level in China

\begin{abstract}
A B S T R A C T
The overall goal of this paper is to analyze the impacts of the urbanization on regional and national agricultural production through its impact on water use in agriculture in China. Given the historical trend of water use in agriculture and its correlation with urbanization, the change in agricultural water use due to urbanization is estimated. Then the impacts of this change on regional crop production are simulated based on the China Water Simulation Model (CWSM). Within CWSM, a positive mathematical programming (PMP) optimizes water allocation among crops and between irrigated and rainfed areas within a crop in each of ten river basins in China. The results show that water use in China has an obvious increasing trend, particularly in the industrial and domestic sectors, while the share of water use in agricultural sector has been dropping. A 1-percentage-point increase in urbanization can result in a 0.47 percentage-point decline in share of water use. Based on the model simulation, this will lead to the further decrease of irrigated areas and the increase of rainfed areas at both the national and river basin levels, particularly for water intensive crops (such as rice and wheat). Accordingly, average yields and total production will also decrease. A river basin with large production of either rice or wheat (or both) decreases more in irrigated area as urban area expands. Adaptation measures are recommended for both authorities and farmers to ensure food security, such as providing incentive for farmers to adopt water saving technology, implementing appropriate institutional and policy innovations (e.g., water use association, water pricing and water use rights).
\end{abstract}

(C) 2015 Elsevier B.V. All rights reserved.

\section{Introduction}

Urbanization in China is one of the most important driving forces that will shape China and global development during the twentyfirst century (Fang, 2009). Urbanization is an inevitable trend in development for China, which is the most populous country in the world. Until 2011, China's urban population was 682 million, accounting for almost one-fifth of the world's urban population and exceeding China's rural population for the first time in history (NBS of China, 2012). It took six decades for China's urbanization to expand from $10 \%$ to $50 \%$; this same process took 150 years in Europe and 210 years in Latin America and the Caribbean (UNDP, 2013). This rapid transition will continue, and, according to the United Nations (2012), China's urbanization level will exceed the world average (53.4\%) in 2014 and reach nearly 70\% in 2030.

\footnotetext{
* Corresponding author. Tel.: +86 1064889841 ; fax: +86 1064856533.

E-mail address: jxwang.ccap@igsnrr.ac.cn (J. Wang).
}

Policy makers in China also have considered urbanization as an important driver for promoting socioeconomic development. It has been well documented that urbanization can play a significant role in unleashing enormous consumption and investment demand, and creating numerous job opportunities (Friedmann, 2006; World Bank, 2014). After an average GDP growth rate of about $10 \%$ in 1978-2008, the growth rate of China's economy has slowed down recently. To maintain its high economic growth, Chinese government has used urbanization to one of major growth engines. For example, urbanization in China was set as one of the key national development strategies for the first time in the 10th Five-Year Plan (2001-2005) (Liu, 2004). The roles of urbanization on China's development have particularly been emphasized in the 12th Five-Year Plan (2011-2015). The plan of the government's top leaders is to increase the rate of urbanization over the next 10 years by 10 percentage points.

Therefore, since the roles of urbanization in socio-economic development and ecological environment are significant (Zhang et al., 2009; Ji, 2011), there has been growing concern on the 
Table 1

Increase and growth rate of water use by sector in different periods in China (1949-2011).

\begin{tabular}{|c|c|c|c|c|c|c|c|c|}
\hline & \multicolumn{4}{|c|}{ Total increase within each period (\%) } & \multicolumn{4}{|c|}{ Annual growth rate (\%) } \\
\hline & Total & Agriculture & Industry & Domestic & Total & Agriculture & Industry & Domestic \\
\hline 1949-1965 & 166 & 154 & 654 & 200 & 6.31 & 6.01 & 13.46 & 7.11 \\
\hline $1965-1980$ & 62 & 45 & 152 & 1456 & 3.26 & 2.53 & 6.37 & 20.08 \\
\hline 1980-1993 & 17 & 3 & 98 & 70 & 1.23 & 0.24 & 5.41 & 4.15 \\
\hline 1993-2000 & 6 & -1 & 26 & 21 & 0.80 & -0.13 & 3.33 & 2.77 \\
\hline $2000-2011$ & 9 & -1 & 28 & 37 & 0.79 & -0.10 & 2.29 & 2.93 \\
\hline $1949-2011$ & 481 & 274 & 5991 & 13065 & 2.88 & 2.15 & 6.85 & 8.19 \\
\hline
\end{tabular}

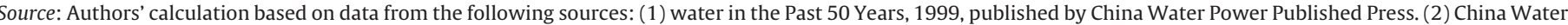
Resources Bulletin (1997-2011), Ministry of Water Resources.

impacts of rapid urbanization on shifting resources from agriculture to non-agriculture and potential impact on China's food security (Satterthwaite et al., 2010). Based on literature review, most of recent studies have focused on the impacts of urbanization on food security through its impacts on cultivated land. For example, Chen (2007) found that in the past 30 years, $21 \%$ of the total loss of cultivated land was converted to urban use. However, Deng et al. (2012) pointed out that urbanization might slow down the rate at which cultivated land is lost in China. In addition to land, rapid urbanization also places a strain on water allocation between rural and urban areas. Some studies have suggested that urbanization can result in large decrease of water use in agriculture (Meinzen-Dick and Appasamy, 2001; Kendy et al., 2007; Wu and Tan, 2012). Interestingly, although water is very scarce and its important role on sustaining agricultural production and ecological system has been significantly addressed by many scholars (such as Boelee, 2011; Wang et al., 2013), little study has examined the impacts of urbanization on regional and national agricultural production through its impacts on water uses.

Faced with rapid urbanization and its pressure on food security, several questions can be raised: What are impacts of urbanization on agricultural water use or how much water used in agricultural sector will be reallocated to other sectors due to urbanization in China? What are the potential impacts of falling water use in agriculture due to urbanization on regional and national crop production and production structure? Specifically, given the change in agricultural water supply in each region, how will water allocation to different crops and the irrigated and rainfed areas of each crop change in each region? What are likely impacts on crop yield and production at regional and national levels? What are implications to China's food security?

The overall goal of this paper is to provide some answers to the above questions through analyzing the impacts of urbanization on agricultural water use and resulted impacts on crop areas, yield and production at the regional and national level in China. In order to realize the goal, we have conducted the following studies. First, based on historical data, we examine the relationship between urbanization and agricultural water use in China. Then the change in total agricultural water use due to urbanization is estimated by using econometric method. Second, the impacts of the change in agricultural water use due to urbanization on regional crop production are simulated based on the China Water Simulation Model (CWSM). CWSW divides China into ten river basins (Liaohe, Songhuajiang, Haihe, Huaihe, Yellow, Yangtze, Pearl, Southeast, Southwest and Northwest river basins). Within CWSM, a positive mathematical programming (PMP) can optimize water allocation among crops and between irrigated and rainfed areas within a crop in each of ten river basins in China. Finally, based on CWSM simulation, the impacts of urbanization through water on crop yield and production are further explored at each river basin and China as a whole.
The rest of this paper is organized as follows. Section 2 analyzes China's historical trend of water use and the correlation between urbanization and agricultural water use. The parameter measuring the impacts of urbanization on agricultural water use obtained in this section is used in a shock to a simulation model, the China Water Simulation Model (CWSM), which is briefly introduced in Section 3. Section 4 presents the simulation results on the impacts of urbanization on irrigated and rainfed crops areas, crop yield and production at both the river basin and national levels. Section 5 concludes with policy implications.

\section{The relationship between trends of water use by sector and urbanization}

\subsection{Trends of China's water use}

Over the past 65 years, water use in China has displayed an obvious increasing trend, particularly before 1993. From 1949 to 2011, the total water use in China rose by $481 \%$ and the annual growth rate reached $2.88 \%$ (Table 1 ). Due to low levels of water use and socioeconomic development, the rate of increase of total water use was highest in 1949-1965. For example, during this period, total water use increased by $166 \%$ with an average annual growth rate of $6.31 \%$. The second highest growth rate occurred in 1965-1980. In this period, the total increase of water use was $62 \%$ and the average annual growth rate was 3.26\%. From 1980 to 1993, total water use in China continued to rise with socioeconomic development. Although the growth rate of water use has been falling, its total use still increased by $17 \%$ with an average annual growth rate of $1.23 \%$ in $1980-1993$. After 1993 , despite further demand for water use from various sectors, the growth rate of water use decreased substantially, because of the rising pressures of water scarcity and increasing water use efficiency in various sectors (Huang et al., 2009; Hubacek et al., 2009; Wang et al., 2009a,b). In 1993-2011, the total water use increased by about $15 \%$ and the average annual growth rate fell to less than $1 \%$. Consistent with the change trend of total water use, water use in three sectors (the agricultural, industrial, and domestic sectors) had high rates of increase until 1993, at which point the growth began to decrease significantly.

Despite presenting similar trends, both the industrial and domestic sectors had much higher growth rates than the agricultural sector did. For example, since 1949, industrial water use increased by nearly 60 times and domestic water use increased by 130 times, while the total use by the agricultural sector only increased by $274 \%$. Similar results can be found for various periods. After 1980, agricultural water use has had a much lower rate of increase (an annual increase of $0.24 \%$ from 1980 to 1993), and since 1993 , the rate has been in decline, since 1993, both industrial and domestic water use have displayed increasing trends.

With the rapid expansion of industrial and domestic water use and the constraints on its limited water supply, China's agricultural sector has faced serious competition pressure for water. For 


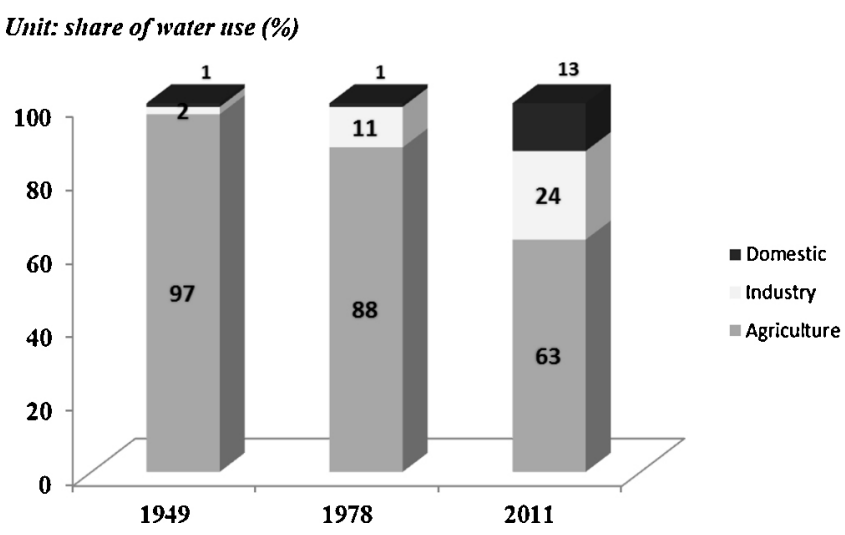

Fig. 1. Water use competition among sectors. Source: Authors' calculation based on water data from the following several source: (1) water in the Past 50 Years, 1999, published by China Water Power Published Press. (2) Water China Water Resources Bulletin (1997-2011), Ministry of Water Resources.

example, in 1949, $97 \%$ of total water use was allocated to the agricultural sector, while $3 \%$ was allocated to the industrial and domestic sectors (Fig. 1). With the rapid increase of nonagricultural water use from the industrial and domestic sectors, agricultural water use declined to $88 \%$ prior to the beginning of rural reform in 1978. Presently, agricultural water use accounts for only $63 \%$ of total water use, while the share of industrial water use is now $24 \%$ and the share of domestic water use is $13 \%$. In the future, it will be impossible for China to significantly increase water use for all its sectors because of water supply limitations. In order to satisfy increasing demand from non-agricultural sectors, part of water resources may have to be reallocated from the agricultural sector.

\subsection{Relationship between agricultural water use and urbanization}

As discussed above, agricultural water use has been challenged by increasing industrial and domestic water use. Many factors have led to increases of industrial and domestic water use, urbanization is one of the major causes. As urbanization expands, increasing numbers of rural residents move to cities, and their domestic water use increases because of improved living standards. For example, from 2006 to 2010, the per-capita water use quota for urban residents was 2081 , or nearly three times that for rural residents in China (Ministry of Water Resources of China, 2006-2010). Industrial water use has also experienced an increasing trend with the expansion of industry under the development of urbanization. Therefore, in order to have a better understanding of future change in the trend of agricultural water use in China, it is necessary to analyze the relationship between agricultural water use and urbanization. The purpose of this section is to examine this relationship based on descriptive statistical analysis and regression estimation.

Historical data for the past 20 years indicate an obvious negative correlation between the share of agricultural water use and the urbanization rate in China. As shown in Fig. 2, from 1993 to 2011, the share of agricultural water use in China declined from $73 \%$ to $63 \%$, a decline of $10 \%$. At the same period, the urbanization rate increased from $28 \%$ to $51 \%$, an increase of $23 \%$. This implies that an approximate 2-percentage-point increase in China's urbanization rate may result in a 1-percentage-point drop in the share of agricultural water use (Fig. 3 ).

In order to further quantify the relationship between agricultural water use and urbanization in China, based on historical data from 1993 to 2011, we specify the following regression model:

$W_{t}=F\left(U_{t}\right)$
Unit: \%

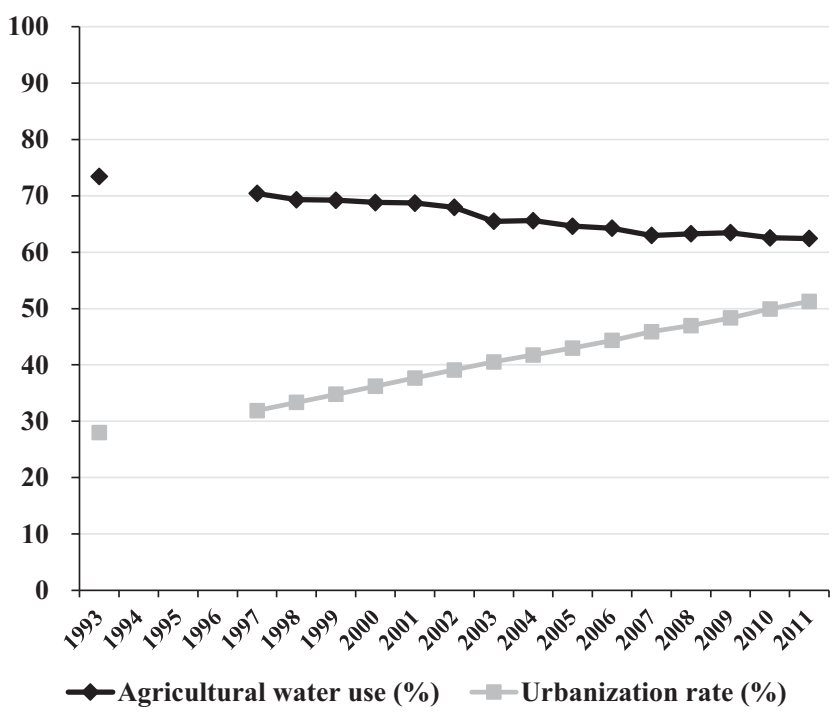

Fig. 2. Correlation between agricultural water use and urbanization.

In the above model, we use the following three alternative indicators to measure agricultural water use in year $t\left(W_{t}\right)$, quantity $\left(10^{8} \mathrm{~m}^{3}\right)$ of agricultural water use, linear and $\log$ form of ratio of agricultural water use to total water use. For the independent variable $U_{t}$, the level of urbanization is measured in two alternative ways, the urbanization rate (ratio of the urban population to the total population) and the log form of urbanization rate.

Based on alternative measurements of the dependent and independent variables, we run three kinds of regressions. The results are presented in Table 2. The estimation results show that all three models perform well. The adjusted $R^{2}$ ranges from 0.22 to 0.95 , which implies that the urbanization rate is an important variable in explaining the share of agricultural water use. The $t$-statistical values of the urbanization rate are all negative and statistically significant, which indicates that urbanization significantly reduces the share of water used in agriculture in China. This is consistent with the above descriptive statistical analysis. Since the second regression has the highest adjusted $R^{2}$, we use its estimation result for the following simulation analysis. According to this model, a 1-percentage-point increase in urbanization reduces the share of China's agricultural water use by 0.47 percentage points.

\section{Simulation model}

To examine the impacts of urbanization on regional and national water allocation and crop production in China, we use CWSM model. CWSM balances water demand and supply and allocates water among its users in each of major river basins in China (Wang et al., 2013). CWSW includes all ten river basins in China. The model includes two major components, water balance and water allocation components. When water balance between the water supply and water demand changes because of policy adjustments or socioeconomic development (such as urbanization), water is reallocated among sectors (agricultural, industrial and domestic water users) and within agricultural sector (among nine groups of crops, rice, wheat, maize, soybean, sugar crops, edible oil crops, cotton, vegetable and other crops). The detail introduction about water balance component of CWSM can be found in Wang et al. (2013). In the following discussion, we mainly focuses on water allocation component for agricultural sector, which has been further developed based on the study of Wang et al. (2013). 


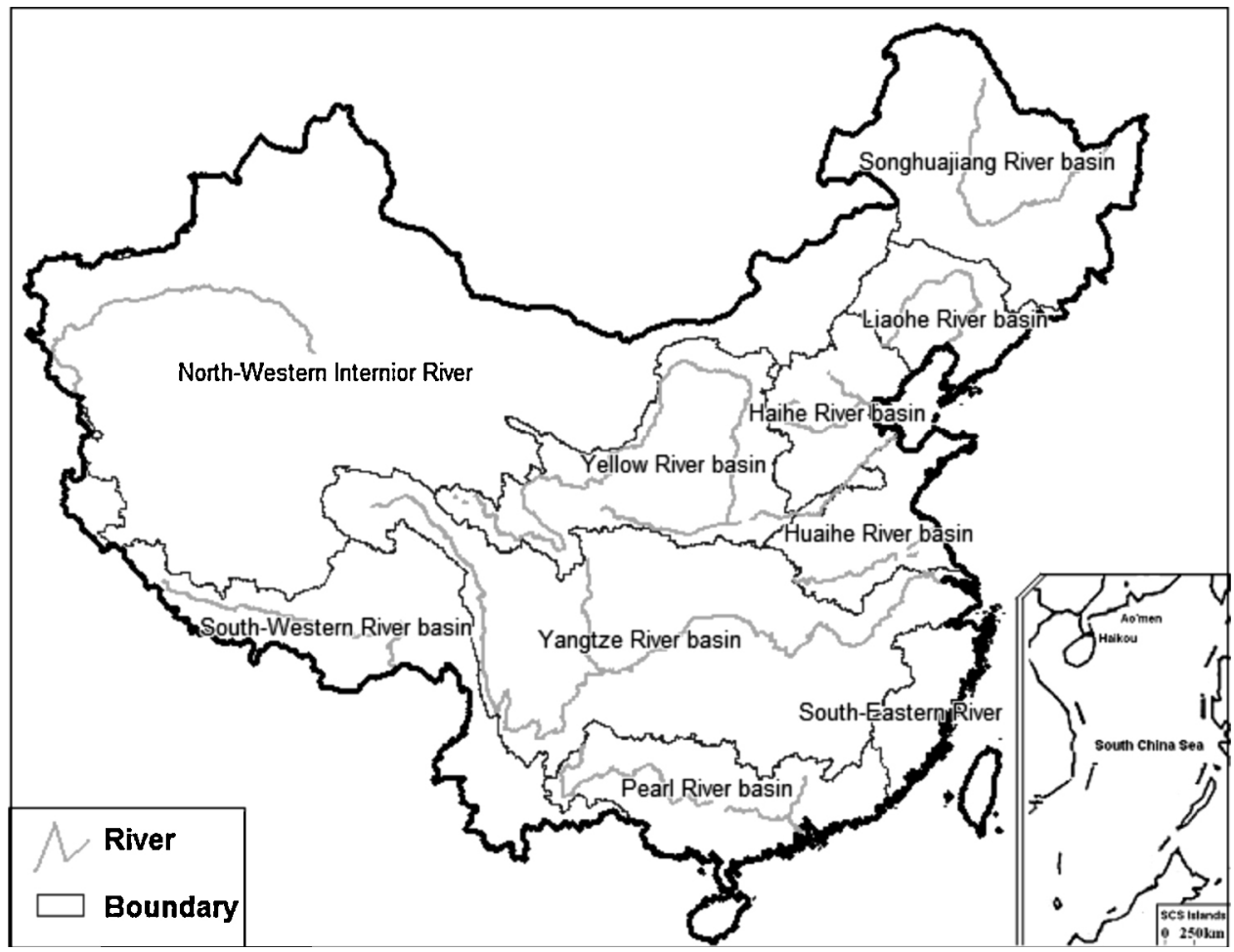

Fig. 3. Locations of ten river basins in China.

The major approach used in water allocation within agricultural sector in CWSM is the positive mathematical programming (PMP) model (Wang et al., 2013). Howitt (1995) firstly formalized the model and then it has been further developed by several scholars thereafter (such as Helming, 2005; He et al., 2012). It is a method for calibrating models of agricultural production with resource constraints using nonlinear production or cost functions, avoiding the corner solution in linear optimization model. The method is implemented in three stages. First, calibration constraints are added to the primal problem. Second, the marginal values from the calibration constraints are used to estimate the parameters of a new cost function. At last, a non-linear objective function is specified and it removes the calibration constraints and reproduces the base-year activity levels, closely or exactly, as unconstrained solution values to verify model calibration. In the literature, some scholars used input-output approach to analyze water allocation and management issues (Zhang et al., 2011; Chen and Chen, 2013; Han et al., 2014).

In the previous study by Wang et al. (2013), an undesirable nature of the original PMP model is that the production of the same crop using different technologies (e.g., irrigated wheat and rainfed wheat) is treated as multiple and totally different activities. In addition, the direct link between water and yield was not established. That is, when water supply has been affected by urbanization, the yield of irrigated crop cannot change accordingly. In order to overcome these two shortcomings, we have made two major improvements. First, according to the approach proposed by Röhm and Dabbert (2003), we have added more calibration constraints to obtain higher substitution elasticity between irrigated and rainfed production of the same crop. Second, we have introduced a yield function to better depict the relationship between crop yield and irrigation water.

The optimal water allocation program used in this study includes the following equation system:

$$
\left\{\begin{array}{c}
\operatorname{Max} A_{r, x c, i r r i} \\
A_{r, x c, r f}
\end{array}\right\} \begin{aligned}
& \Pi=\sum_{x c}\left[A_{r, x c, i r r i}\left(Y_{r, x c, i r r i} P_{r, x c}-A C_{r, x c, i r r i}\right)\right. \\
& \\
& \\
& \left.+A_{r, x c, r f}\left(Y_{r, x c, r f} P_{r, x c}-A C_{r, x c, r f}\right)\right]
\end{aligned}
$$

Table 2

Regression results on the impacts of urbanization on agricultural water use in China.

\begin{tabular}{llll}
\hline & Dependent variable & & \\
\cline { 2 - 4 } & Quantity of agricultural water use & Ratio of agricultural water use & Ratio of agricultural water use (log form) \\
\hline $\begin{array}{l}\text { Ratio of urban population over } \\
\text { total population }\end{array}$ & $-947.28^{* * *}$ & $-0.47^{* * *}$ & $(17.07)$ \\
$\begin{array}{l}\text { Ratio of urban population over } \\
\text { total population (log form) }\end{array}$ & & & $-0.27^{* * *}$ \\
$R$-squared & $0.27)$ & & $(16.35)$ \\
\hline
\end{tabular}

Note: There are 16 observations; absolute value of $t$ statistics in parentheses.

S*** Significant at $1 \%$. 


$$
\begin{aligned}
& \sum_{x c}\left(A_{r, x c, i r r i}+A_{r, x c, r f}\right) \leq \sum_{x c}\left(\bar{A}_{r, x c, i r r i}+\bar{A}_{r, x c, r f}\right) \\
& \frac{\sum_{x c} E T_{r, x c} A_{r, x c, i r r i} I_{r, x c}}{\theta_{r}} \leq W_{r} \\
& Y_{r, x c, i r r i}=\chi_{r, x c} I_{r, x c}^{2}+\gamma_{r, x c} I_{r, x c}+\bar{Y}_{r, x c, r f} \\
& I_{r, x c}=a_{r, x c}\left(1-e^{-b_{r, x c}} \sum_{r, x c, i r r i}^{A_{r, x c, l}}\right) \\
& A_{r, x c, i r r i} \leq \bar{A}_{r, x c, i r r i}\left(1+\varepsilon_{1}\right) \quad\left[\mu_{r, x c, i r r i}\right] \\
& A_{r, x c, r f} \leq \bar{A}_{r, x c, r f}\left(1+\varepsilon_{1}\right) \quad\left[\mu_{r, x c, r f}\right] \\
& \sum_{x c}\left(A_{r, x c, i r r i}+A_{r, x c, r f}\right) \leq \sum_{x c}\left(\bar{A}_{r, x c, i r r i}+\bar{A}_{r, x c, r f}\right)\left(1+\varepsilon_{2}\right) \quad\left[\mu_{r, x c}\right]
\end{aligned}
$$

where Eq. (2) is the objective function, which is used to maximize the producer's profit $\prod$ subject to land constraints (3), water constraints (4), yield constraints (5), irrigation level constraints (6), and calibration constraints (7)-(9). The subscript $r$ refers to river basins (Liaohe, Songhuajiang, Haihe, Huaihe, Yellow, Yangtze, Pearl, Southeast, Southwest, and Northwest River Basins); $x c$ refers to crops (rice, wheat, maize, soybean, sugar crops, edible oil crops, cotton, vegetables, and other crops); irri refers to irrigated land and $r f$ refers to rainfed land.

The following are the definitions of variables in the model system:

$A_{r, x c, i r r i}$ and $A_{r, x c, r f}$ : the main choice variables in this model, indicating the areas of irrigated and rainfed production by crop in each river basin;

$Y_{r, x c, i r r i}$ and $Y_{r, x c, i r r i}$ : yield of irrigated and rainfed crops in each river basin;

$P_{r, x c}$ : output price by crop in each river basin;

$A C_{r, x c, i r r i}$ and $A C_{r, x c, r f}$ : average production cost of irrigated and rainfed crops in each river basin;

$\bar{A}_{r, x c, i r r i}$ and $\bar{A}_{r, x c, r f}$ : observed sown area of irrigated and rainfed crops in each river basin in the base year;

$I_{r, x c}$ : irrigation level of irrigated crops in each river basin, $I_{r, x c} \in[0$, $1]$;

$E T_{r, x c}$ : net evapotranspiration by crop in each river basin;

$\theta_{r}$ : irrigation water use efficiency in each river basin;

$W_{r}$ : irrigation water supply in each river basin;

$\chi_{r, x c, i r r i}$ and $\gamma_{r, x c, i r r i}$ : parameters representing the relationship between irrigated crop yield and irrigation in each river basin;

$a_{r, x c, i r r i}$ and $b_{r, x c, i r r i}$ : parameters representing the relationship between irrigation and the share of irrigated land area in each river basin;

$\varepsilon_{1}$ and $\varepsilon_{2}$ : small positive numbers, $\varepsilon_{2}<\varepsilon_{1}$;

$\mu_{r, x c, i r r i}, \mu_{r, x c, r f}$ and $\mu_{r, x c}$ : the shadow values of calibration constraints, associated with irrigated area, rainfed area and total sown area of each crop, respectively.

In the objective Eq. (2), a crop's profit is defined as the difference between revenue and the cost of crop production. A crop's average revenue is the product of its yield and its output price. The average cost of crop production in the first step of PMP is the summation of all kinds of costs per hectare, including material and water costs. Land constraints ( 3 ) require that the total area allocated to crops under irrigated and rainfed production does not exceed the total land available. Water constraints (4) imply that irrigation water use in each river basin cannot be more than the irrigation water supply. Irrigation water use is equal to the result of dividing agricultural water demand for all crops (a crop's net evapotranspiration multiplied by crop area) by irrigation efficiency.
Given the responses of crop yields to irrigation water, we apply a non-linear yield function for Eq. (5). The crop yield of irrigated land in the equation is not constant, but a variable determined by the observed rainfed yield and the irrigation level. The parameters in this function $\left(\chi_{r, x c, i r r i}\right.$ and $\left.\gamma_{r, x c, i r r i}\right)$ are derived using observed information and based on Eq. (10) (expression of yield response to ET), proposed by the FAO (Doorenbos and Kassam, 1979):

$\left(1-\frac{Y_{a}}{Y_{x}}\right)=K_{y}\left(1-\frac{E T_{a}}{E T_{x}}\right)$

where $Y_{x}$ and $Y_{a}$ are the maximum and actual yields, respectively, $E T_{x}$ and $E T_{a}$ are the maximum and actual evapotranspiration, respectively, $K_{y}$ is a yield response factor representing the effect of a reduction in evapotranspiration (ET) on yield losses, and the values of $K_{y}$ are from the FAO's Irrigation and Drainage Paper No. 66 (Steduto et al., 2012). China's elasticity of crop yield to irrigation water is about 0.35 overall, ranging from 0.04 to 0.9 for nine crops in ten river basins, which is comparable with the elasticities in related studies (Cortignani and Severini, 2009; Graveline and Mérel, 2014).

As assumed in irrigation level constraints (6), the irrigation level of a crop is positively correlated with the ratio of the irrigation area to the total sown area. Irrigation level measures to what extent the net irrigation demand of a crop is satisfied and is defined as the ratio of the actual irrigation water used by a crop to its net demand for irrigation. The more serious the water shortage is, the more reduction the irrigation area and irrigation level will experience. Parameter $b_{r, x c, i r r i}$, which is 1.045 for the whole country and significant at the $1 \%$ level, which is estimated based on the field survey data collected by the Center for Chinese Agricultural Policy of Chinese Academy of Sciences. Parameter $a_{r, x c, i r r i}$ is derived using the observed data in the base year. Without considering technology improvements, the irrigation level changes only slightly with the share of the irrigation area. Thus, in our model, farmers can choose an irrigation level within a reasonable range (within 10\% of the given irrigation level at the base year) instead of choosing among certain irrigation methods (such as deficit irrigation at 5\% or $10 \%$ in Cortignani and Severini (2009)).

There are three calibration constraints represent by (7)-(9). The shadow values of these constraints are used in the new average cost function:

$A C_{r, x c, i r r i}=\alpha_{r, x c, i r r i}+\frac{1}{2} \beta_{r, x c, i r r i} A_{r, x c, i r r i}+\frac{1}{2} \gamma_{r, x c}\left(A_{r, x c, i r r i}+A_{r, x c, r f}\right)$

$A C_{r, x c, r f}=\alpha_{r, x c, r f}+\frac{1}{2} \beta_{r, x c, r f} A_{r, x c, r f}+\frac{1}{2} \gamma_{r, x c}\left(A_{r, x c, r f}+A_{r, x c, r f}\right)$

in which, $\quad\left\{\begin{array}{l}\alpha_{r, x c, \text { irri }}=C_{r, x c, \text { irri,material }}+C_{r, x c, \text { irri,water }} I_{r, x c, \text { irri }} \\ \alpha_{r, x c, r f}=C_{r, x c, r f, \text { material }}\end{array}\right.$, $\left\{\beta_{r, x c, i r r i}=\left.\mu_{r, x c, i r r i}\right|_{\bar{A}, x c, i r r i}\right.$ (for nonzero activities), and $\left\{\begin{array}{l}\beta_{r, x c, r f}=\mu_{r, x c, r f} / \bar{A}_{r, x c, r f} \\ \beta_{r, x c}=\mu_{r, x c} /\left(A_{r, x c, i r n}+A_{r, x c, r f}\right.\end{array}\right.$ $\gamma_{r, x c}=\mu_{r, x c} /\left(\bar{A}_{r, x c, i r r i}+\bar{A}_{r, x c, r f}\right)$. These substitutions make the calibration constraints redundant, and the objective function (2) with the new cost functions (11) and (12) is maximized subject to the constraints (3)-(6), where the base year information can be fully replicated. The definition of $\beta$ does not allow the consideration of activity that is not present in the base year. Although this limitation is considered as a shortcoming and is overcome by Cortignani and Severini (2009), it suits our model well because unobserved activities, such as rice production without irrigation in northern China, are unlikely to develop. Additional information, such as the actual land value of each river basin, is used to calibrate the least profitable crop and activity following the procedure in Röhm and Dabbert (2003).

Using the extended PMP model, cropping patterns can be quantified by $\left(A_{r, x c, i r r i}+A_{r, x c, r f}\right)$, while irrigation strategies can be 
quantified by $A_{r, x c . i r r i}$ for irrigated areas, $A_{r, x c, r f}$ for rainfed areas and $I_{r, x c, i r r i}$ for the irrigation level. In this case, the simulation's results are more practical and reasonable than those under the original PMP model.

\section{Simulated results on the impacts of urbanization on crop area and production by river basin}

\subsection{Scenarios' design}

We design two scenarios for the impact simulations. The first scenario is the optimal allocation scenario. This is done by running the PMP model of CWSM to obtain the optimal solutions of water allocations among crops and by irrigated and rainfed areas within each crop in each of ten river basins in 2010 (or the base year). To avoid unreasonable results on changes in irrigation, we also impose a maximum of $10 \%$ (either positive or negative) change in irrigation level for each crop in each river basin.

The second scenario is the urbanization scenario. That is, on the top of the optimal scenario, we consider a 1-percentage-point increase in urbanization. Based on econometric results in Section 2 , we know that a 1-percentage-point increase in urbanization reduces the share of agricultural water use by 0.47 percentage points in China. We incorporate this result $(-0.47 \%)$ in the PMP model of CWSM for all river basins to re-simulate the optimal allocations of water, since we mainly focus on the impacts of urbanization through agricultural water use.

The differences on irrigated and rainfed areas by crop and by river basin between the above two scenarios are the impacts of a 1-percentage-point increase in urbanization. Finally, based on the changes in irrigated and rainfed areas by crop, the impacts of urbanization on average crop yields and production at the river basin and national level can be estimated. In the following discussion, we mainly focus on the impacts of a 1-percentage-point increase in urbanization on each crop area and production at the river basin and national level.

\subsection{The impacts of urbanization on irrigated, rainfed and sown} area

The simulation results show that because of the decrease in agricultural water use under the urbanization scenario, the total irrigated area decreases, while rainfed area increases throughout China. If the urbanization rate increases by a 1-percentage-point from the base year, the total irrigated area for all crops in China decreases by $0.48 \%$, while rainfed area increases by $0.31 \%$ (columns 2-3, Table 3).

Similar change trends are also found in all ten river basins (columns 2-3, Table 4). The decrease of irrigated areas in all river basins ranges from $0.21 \%$ in the Northwest River Basin to $0.64 \%$ in the Yangtze River Basins, and increase of rainfed areas in all river basins ranges from $0.12 \%$ in the Yellow River Basin to $0.73 \%$ in the Northwest River Basin. Among ten river basins, decreases of irrigated areas in five river basins (Liaohe, Haihe, Yangtze, Peal and Southeast River Basins) are higher than national average level; and increases of rainfed areas in six river basins (Liaohe, Haihe, Yangtze, Southeast, Huaihe and Northwest) are higher than national average level. Obviously, the lowest decrease of irrigated areas and highest increase in rainfed areas all take place in the Northwest River Basin. However, due to low precipitation and limited water supply, the further development opportunity for rainfed agriculture in Northwest River Basin is very limited and presently, rainfed agriculture in this river basin only consists of $23 \%$ of total production. Therefore, under the urbanization background, how to ensure sufficient irrigation water supply in the Northwest River Basin is a challenge.
However, the impacts of urbanization on irrigated and rainfed areas differ largely by crop (columns $2-3$, Table 3 ). In China, most crops (except soybeans) reduce irrigated areas and increase rainfed areas with urbanization. In general, for crops with relatively higher water sensitivity under irrigation, such as rice and wheat, farmers prefer to stop irrigating in some areas when the water supply shrinks due to urbanization. When urbanization increases by a 1percentage-point, which result in 0.47 percentage-point decline in agricultural water use when other factors have been kept constant (those factors influences by urbanization, such as labor wage, land allocation between rural and urban regions), rice declines its irrigated areas by as high as $0.83 \%$. Following with rice, the reduction of irrigate areas for both wheat and maize also reach by $0.58 \%$ and $0.38 \%$, respectively, and meantime their rainfed areas increase by $0.45 \%$ and $0.24 \%$. The reduction of irrigated areas for other crops (such as sugar crops, oil crops, cotton, vegetable and other crops) are all lower than that for rice, wheat and maize, ranging from $0.06 \%$ to $0.11 \%$. Different from most crops, both irrigated and rainfed areas of soybean tend to increase (by $0.12 \%$ and $0.35 \%$ respectively). The results imply that faced with reduction of agricultural water supply resulted from urbanization, farmers tend to reallocate land from other crops to soybeans to ensure their profit.

Similar to the simulation results at the national level, the changes in irrigated area also vary by crop in each river basin (column 2, Table 4). When urbanization increases by a 1-percentage-point and keeping constant of other factors, the reduction of irrigated areas for rice in the Huaihe $(1.04 \%)$ and Yangtze River Basin (0.87\%) are higher than other eight river basins. For wheat, except in the Pearl River Basin (where wheat irrigated areas increases by $0.38 \%$ ), its reduction of irrigated areas $(6.42 \%)$ is obviously higher in the Liaohe River Basin than other eight river basins (near or lower than 1\%). Unlike rice and wheat whose irrigated areas decline in most river basins, irrigated areas for maize in most river basins tend to increase and only decrease in two river basins, Liaohe and Haihe River Basin. It possibly implies that maize requires less irrigation but having relatively higher profits among grain crops. If the river basin is not with serious water shortage (not like in the Liaohe and Haihe River Basin), farmers tend to switch some irrigated areas from those grain crops that require more irrigation but having lower profit (such as rice and wheat) to maize. Like maize, irrigated areas for soybean and oil crops increase in most river basins due to their relatively lower irrigation requirement and higher profit. For sugar crops, cotton and vegetable, when urbanization increases, their irrigated areas present decrease trend in most of river basins and such change trend is similar to rice and wheat.

Different from the change trends of irrigated areas, rainfed areas show less diversity (column 3, Table 4). When urbanization increases by a 1-percentage-point, and keeping constant of all other factors, wheat in Songhuajiang, Yangtze and Southwest River Basins, sugar crops in Liaohe and Songhuajiang River Basins, vegetable in Haihe and Southwest River Basins will decrease slightly. Other than those, most crops in most of river basins their rainfed areas present increase trend. For example, rainfed areas for wheat increase by $6.55 \%$ in the Liaohe River Basin, which is much higher than that in other river basins. Rainfed areas for maize increase by $0.76 \%$ in the Northwest River Basin and $0.46 \%$ in the Liaohe River Basin. In these two River Basins, rainfed areas for cotton will also increase by $0.29 \%$ (column 3 , Table 4 ). Under urbanization, the increases of rainfed areas in ten river basins mainly come from grain crops, namely rice in Yangtze, Pearl and Southeast River Basins, wheat in Huaihe, Yellow and Northwest River Basins, maize in Liaohe, Haihe and Southwest River Basins, and Soybean in Songhuajiang River Basin.

Finally, simulation results indicate that urbanization leads to change in sown area of each crop but the change differs among 
Table 3

Impacts of a 1-percentage-point increase in urbanization on crop production in China.

\begin{tabular}{|c|c|c|c|c|c|}
\hline & Sown area (\%) & Irrigated area (\%) & Rainfed area (\%) & Average yield (\%) & Total production (\%) \\
\hline Total area & 0.00 & -0.48 & 0.31 & & \\
\hline Rice & -0.29 & -0.83 & 1.19 & -0.15 & -0.44 \\
\hline Wheat & -0.01 & -0.58 & 0.45 & -0.10 & -0.11 \\
\hline Maize & 0.08 & -0.38 & 0.24 & -0.05 & 0.03 \\
\hline Soybean & 0.31 & 0.12 & 0.35 & -0.02 & 0.29 \\
\hline Sugar crops & 0.03 & -0.08 & 0.05 & 0.00 & 0.03 \\
\hline Oil crops & 0.16 & -0.07 & 0.21 & -0.01 & 0.14 \\
\hline Cotton & 0.03 & -0.18 & 0.26 & -0.03 & 0.00 \\
\hline Vegetable & 0.00 & -0.06 & 0.04 & -0.01 & -0.01 \\
\hline Other crops & 0.03 & -0.11 & 0.06 & -0.01 & 0.02 \\
\hline
\end{tabular}

Source: Simulation results from CWSM model.

crops (column 1, Tables 3 and 4). At the national level, sown areas of only two crops (rice and wheat) decrease with urbanization (Table 3). Since rice mainly depends on irrigation, it is not surprising to find the highest decrease of sown area for rice. For other crops, although their irrigated areas tend to decrease, possibly due to higher increase of rainfed areas (such as higher increase percentage of rainfed areas for soybean, oil crops and cotton), their crop sown areas have not been reduced. As for the results by river basin (column 1, Table 4), mostly the changes of crop sown areas are consistent with that at the national level.

\subsection{The impacts of urbanization on average crop yield and production}

Since urbanization results in fall in irrigated areas for most crops, the average yield of most crops in China decrease with urbanization accordingly (column 4, Table 4). Simulation results show that when urbanization increases by a 1-percentage-point, except for sugar crops, the average yield of all crops decreases. The highest reduction in average yield is found in rice (by $0.15 \%$ ) at the national level. The second and third major crops having higher reduction of average yield are wheat and maize, reducing by $0.15 \%$ and $0.10 \%$, respectively. The yield reduction for other crops range from $0.01 \%$ to $0.05 \%$. As for the impacts of urbanization on crop yield by river basin, although they differ across ten river basins, the directions of impacts are similar to those at the national level. Reduction in rice yield is highest in the Pearl River Basin (0.15\%) and for wheat and maize, their yield reduction is highest in the Liaohe River Basin (1.52\%) and Haihe River Basin (0.15\%).

The impacts of urbanization on crop production are estimated based on the simulated results of changes in crop sown area and average yield. The results are presented in the last column of Tables 3 and 4. Interestingly, the fall in production in China is found only for rice, wheat and vegetables (Table 3 ), the most intensive water use crops. In fact, the reduction of production of rice or wheat production is not only due to reduction of its average yield, but also the reduction of its sown areas. For vegetable, reduction of its production is mainly due to the decline of average yield since its sown areas has not been changed. For other crops, even their average yields decline, their productions do not fall. The major reason is that their sown areas increase, which offsets the negative impact of urbanization on yield reduction.

The results on the impacts of urbanization on crop production by river basin show that the nature of impacts highly depends on the type of crops planted and composition of crops in each river basin. For those regions with more production in rice and wheat, the more negative impacts on crop production are evidenced (last column, Table 4). In addition to rice and wheat, in many river basins, the productions of several other crops with relatively less intensive use of water rise slightly. Therefore, urbanization can also result in the changes in crop structure in each river basin.
Finally, we want to address that CWSM is still under the development stage and the stability of magnitude of simulation results need to be further improved in the future study. Presently, some key parameters (such as elasticity of crop yield to irrigation water and elasticity of irrigation level to the share of irrigated area) are mainly based on literature review and do not vary by river basins. Although the directions of simulation results (such as the impacts of urbanization on crop irrigated and rainfed areas, crop yields and production) are stable, their magnitudes are sensitive to the assumption of these key parameters. For example, the negative impact of urbanization on rice production at national level ranges from $0.2 \%$ to $0.6 \%$ under different assumptions on these parameters. In the future, these parameters need to be verified based on empirical study in various regions in China.

\section{Conclusion and policy implications}

This study analyzes the impacts of urbanization on agricultural water use and resulted impacts on crop areas, yield and production at the regional and national level in China. The results of econometric analysis show that the falling share of water used in agriculture has been significantly correlated with the rise of urbanization. A 1-percentage-point rise in the share of urban population has been associated with nearly a half percentage decrease in the share of water used in agriculture. To simulate the impact of urbanization through its impact of agricultural water use, an optimal water allocation program under a water supply and demand balance model is developed.

Simulation results indicate that the larger negative impact of urbanization is in water intensive using crops such as rice and wheat. With a 1-percentage-point rise in urbanization, the total irrigated areas for all crops in China decrease by $0.48 \%$, while rainfed areas increase by $0.31 \%$. The largest falls in irrigated areas are in rice and wheat. Given the yield gap between the irrigated and rainfed crops, the changes in the irrigated areas, together with the corresponding rise in rainfed, result in the falls of rice and wheat production in China by $0.44 \%$ and $11 \%$, respectively. A very mild negative impact is also found in vegetable production $(0.01 \%)$. On the other hand, all other crops that use relatively less water per hectare increase their production slightly, ranging from nearly no change in cotton to a rise of $0.29 \%$ in soybean production. For grain as a whole, a 1-percentage-point rise in urbanization reduces grain production by about $0.17 \%$.

The impacts of urbanization on crop production through its impact on water availability differ by river basin. Among ten river basins, decreases of irrigated areas in five river basins are higher than national average level; and increases of rainfed areas in six river basins are higher than national average level. In general, a river basin with large production of either rice or wheat (or both) decreases more in irrigated area as urban area expands. The impacts of urbanization on irrigated and rainfed areas of each crop also 
Table 4

Impacts of a 1-percentage-point increase in urbanization on crop production by river basin.

\begin{tabular}{|c|c|c|c|c|c|}
\hline & Sown area (\%) & Irrigated area (\%) & Rainfed area (\%) & Average yield (\%) & Total production (\%) \\
\hline \multicolumn{6}{|l|}{ Liaohe RB } \\
\hline Total area & 0.00 & -0.51 & 0.35 & & \\
\hline Rice & -0.50 & -0.50 & 0.00 & 0.00 & -0.50 \\
\hline Wheat & -0.58 & -6.42 & 6.55 & -1.52 & -2.01 \\
\hline Maize & 0.07 & -0.55 & 0.46 & -0.10 & -0.03 \\
\hline Soybean & 0.18 & 0.16 & 0.19 & 0.00 & 0.18 \\
\hline Sugar crops & -0.11 & -0.09 & -0.11 & 0.00 & -0.10 \\
\hline Oil crops & 0.09 & -0.52 & 0.21 & -0.03 & 0.05 \\
\hline Cotton & 0.05 & -0.20 & 0.29 & -0.03 & 0.01 \\
\hline Vegetable & 0.00 & -0.11 & 0.11 & -0.02 & -0.02 \\
\hline Other crops & 0.05 & -0.46 & 0.13 & -0.03 & 0.02 \\
\hline \multicolumn{6}{|l|}{ Songhuajiang RB } \\
\hline Total area & 0.00 & -0.45 & 0.19 & & \\
\hline Rice & -0.64 & -0.78 & 2.62 & -0.06 & -0.71 \\
\hline Wheat & -0.94 & -1.13 & -0.76 & 0.00 & -1.00 \\
\hline Maize & 0.03 & 0.03 & 0.03 & 0.00 & 0.03 \\
\hline Soybean & 0.37 & 0.32 & 0.37 & 0.00 & 0.36 \\
\hline Sugar crops & -0.20 & -0.17 & -0.22 & 0.00 & -0.20 \\
\hline Oil crops & 0.28 & 0.24 & 0.29 & 0.00 & 0.28 \\
\hline Cotton & 0.01 & -0.34 & 0.35 & -0.06 & -0.05 \\
\hline Vegetable & -0.02 & -0.10 & 0.23 & -0.03 & -0.05 \\
\hline Other crops & 0.03 & 0.04 & 0.03 & 0.00 & 0.03 \\
\hline \multicolumn{6}{|l|}{ Haihe RB } \\
\hline Total area & 0.00 & -0.50 & 0.55 & & \\
\hline Rice & -0.38 & -0.38 & 0.00 & 0.00 & -0.38 \\
\hline Wheat & -0.10 & -0.57 & 0.98 & -0.12 & -0.22 \\
\hline Maize & 0.06 & -0.97 & 0.66 & -0.15 & -0.09 \\
\hline Soybean & 0.26 & 0.22 & 0.27 & 0.00 & 0.26 \\
\hline Sugar crops & 0.00 & -0.34 & 0.34 & -0.04 & -0.04 \\
\hline Oil crops & 0.11 & 0.02 & 0.20 & -0.01 & 0.10 \\
\hline Cotton & 0.04 & -0.32 & 0.21 & -0.03 & 0.01 \\
\hline Vegetable & -0.03 & -0.08 & 0.17 & -0.01 & -0.04 \\
\hline Other crops & 0.02 & -0.11 & 0.09 & -0.01 & 0.01 \\
\hline \multicolumn{6}{|l|}{ Huaihe RB } \\
\hline Total area & 0.00 & -0.43 & 0.40 & & \\
\hline Rice & -0.86 & -1.04 & 1.51 & -0.07 & -0.93 \\
\hline Wheat & 0.15 & -0.51 & 0.64 & -0.09 & 0.06 \\
\hline Maize & 0.18 & 0.21 & 0.17 & 0.00 & 0.18 \\
\hline Soybean & 0.37 & 0.31 & 0.44 & 0.00 & 0.37 \\
\hline Sugar crops & -0.34 & -0.34 & 0.00 & 0.00 & -0.34 \\
\hline Oil crops & 0.16 & 0.01 & 0.30 & -0.01 & 0.14 \\
\hline Cotton & -0.05 & -0.61 & 0.66 & -0.11 & -0.16 \\
\hline Vegetable & -0.03 & -0.04 & -0.03 & 0.00 & -0.04 \\
\hline Other crops & 0.06 & -0.21 & 0.18 & -0.05 & 0.01 \\
\hline \multicolumn{6}{|l|}{ Yellow RB } \\
\hline Total area & 0.00 & -0.27 & 0.12 & & \\
\hline Rice & -0.07 & -0.07 & 0.00 & 0.00 & -0.07 \\
\hline Wheat & -0.05 & -0.64 & 0.38 & -0.19 & -0.24 \\
\hline Maize & 0.03 & -0.06 & 0.06 & -0.01 & 0.03 \\
\hline Soybean & 0.05 & -0.03 & 0.06 & 0.00 & 0.04 \\
\hline Sugar crops & 0.01 & -0.08 & 0.07 & -0.02 & -0.01 \\
\hline Oil crops & 0.03 & 0.00 & 0.04 & 0.00 & 0.03 \\
\hline Cotton & 0.01 & -0.02 & 0.03 & 0.00 & 0.01 \\
\hline Vegetable & 0.00 & -0.01 & 0.01 & 0.00 & 0.00 \\
\hline Other crops & 0.00 & 0.00 & 0.00 & 0.00 & 0.00 \\
\hline \multicolumn{6}{|l|}{ Yangtze RB } \\
\hline Total area & 0.00 & -0.64 & 0.33 & & \\
\hline Rice & -0.17 & -0.87 & 1.17 & -0.16 & -0.32 \\
\hline Wheat & -0.02 & -0.02 & -0.03 & 0.00 & -0.02 \\
\hline Maize & 0.15 & -0.57 & 0.28 & -0.04 & 0.11 \\
\hline Soybean & 0.24 & -0.33 & 0.39 & -0.03 & 0.21 \\
\hline Sugar crops & 0.07 & -1.09 & 0.20 & -0.04 & 0.03 \\
\hline Oil crops & 0.18 & -0.38 & 0.24 & -0.01 & 0.17 \\
\hline Cotton & 0.08 & -0.14 & 0.14 & -0.01 & 0.07 \\
\hline Vegetable & 0.01 & -0.07 & 0.05 & -0.01 & 0.01 \\
\hline Other crops & 0.04 & -0.25 & 0.08 & -0.01 & 0.03 \\
\hline \multicolumn{6}{|l|}{ Pearl RB } \\
\hline Total area & 0.00 & -0.50 & 0.29 & & \\
\hline Rice & -0.15 & -0.75 & 1.04 & -0.15 & -0.30 \\
\hline Wheat & 0.44 & 0.38 & 0.45 & 0.00 & 0.43 \\
\hline Maize & 0.11 & 0.12 & 0.11 & 0.00 & 0.11 \\
\hline Soybean & 0.39 & 0.34 & 0.40 & 0.00 & 0.39 \\
\hline
\end{tabular}


Table 4 (Continued)

\begin{tabular}{|c|c|c|c|c|c|}
\hline & Sown area (\%) & Irrigated area (\%) & Rainfed area (\%) & Average yield (\%) & Total production (\%) \\
\hline Sugar crops & 0.06 & 0.05 & 0.06 & 0.00 & 0.06 \\
\hline Oil crops & 0.15 & -0.04 & 0.17 & -0.01 & 0.14 \\
\hline Cotton & 0.06 & -0.04 & 0.08 & 0.00 & 0.05 \\
\hline Vegetable & 0.01 & -0.04 & 0.04 & -0.01 & 0.01 \\
\hline Other crops & 0.02 & -0.12 & 0.06 & -0.01 & 0.01 \\
\hline \multicolumn{6}{|l|}{ Southeast RB } \\
\hline Total area & 0.00 & -0.63 & 0.45 & & \\
\hline Rice & -0.13 & -0.84 & 1.30 & -0.13 & -0.26 \\
\hline Wheat & -0.32 & -4.32 & 1.08 & -0.40 & -0.72 \\
\hline Maize & 0.27 & -0.34 & 0.36 & -0.02 & 0.24 \\
\hline Soybean & 0.49 & -0.40 & 0.59 & -0.03 & 0.47 \\
\hline Sugar crops & 0.12 & 0.11 & 0.13 & 0.00 & 0.12 \\
\hline Oil crops & 0.22 & -0.37 & 0.29 & -0.02 & 0.20 \\
\hline Cotton & 0.18 & -0.23 & 0.22 & -0.01 & 0.17 \\
\hline Vegetable & 0.02 & -0.09 & 0.07 & -0.01 & 0.01 \\
\hline Other crops & 0.06 & -0.15 & 0.08 & -0.01 & 0.05 \\
\hline \multicolumn{6}{|l|}{ Southwest RB } \\
\hline Total area & 0.00 & -0.42 & 0.18 & & \\
\hline Rice & -0.22 & -0.57 & 1.18 & -0.14 & -0.35 \\
\hline Wheat & -0.13 & -0.11 & -0.14 & 0.00 & -0.12 \\
\hline Maize & 0.13 & -0.97 & 0.32 & -0.08 & 0.04 \\
\hline Soybean & 0.24 & 0.21 & 0.24 & 0.00 & 0.24 \\
\hline Sugar crops & 0.02 & 0.02 & 0.02 & 0.00 & 0.02 \\
\hline Oil crops & 0.09 & 0.08 & 0.10 & 0.00 & 0.09 \\
\hline Cotton & 0.04 & -0.50 & 0.17 & -0.04 & -0.01 \\
\hline Vegetable & -0.01 & -0.01 & -0.01 & 0.00 & -0.01 \\
\hline Other crops & 0.01 & 0.01 & 0.01 & 0.00 & 0.01 \\
\hline \multicolumn{6}{|l|}{ Northwest RB } \\
\hline Total area & 0.00 & -0.21 & 0.73 & & \\
\hline Rice & -0.10 & -0.10 & 0.00 & 0.00 & -0.10 \\
\hline Wheat & -0.25 & -1.05 & 3.25 & -0.27 & -0.49 \\
\hline Maize & 0.09 & -0.03 & 0.76 & -0.04 & 0.05 \\
\hline Soybean & 0.31 & -0.03 & 1.68 & -0.21 & 0.13 \\
\hline Sugar crops & -0.16 & -0.16 & 0.00 & 0.00 & -0.16 \\
\hline Oil crops & 0.21 & 0.25 & 0.15 & 0.00 & 0.22 \\
\hline Cotton & 0.06 & 0.03 & 0.23 & -0.01 & 0.05 \\
\hline Vegetable & 0.01 & 0.01 & 0.00 & 0.00 & 0.01 \\
\hline Other crops & 0.01 & 0.01 & 0.01 & 0.00 & 0.01 \\
\hline
\end{tabular}

Source: Simulation results from CWSM model.

differ slightly among ten river basins. For crops with relatively higher water sensitivity, farmers tend to reduce irrigated area and expand rainfed area when the water supply shrinks due to urbanization. Meantime, rainfed areas for all crops in most of river basins increase with urbanization. When we examine the impacts of urbanization on crop production by river basin, we also find that the river basins with more rice or wheat production are more negatively influenced by urbanization.

The results of this paper have several policy implications. First, while the roles of urbanization in development are obvious, its negative impacts on the irrigated agriculture, particular the productions of rice and wheat, the most important food grain in China, should get more attention. Second, given the constant of all other factors, urbanization tends to favor the rainfed crop expansion and change regional cropping pattern, which may also have policy implications on investment priority in rainfed agriculture. The last but not the least, in order to reduce the loss of irrigated agriculture from rapid urbanization, adopting water saving technology and providing incentive for farmers to improving irrigation water use efficiency are essential (Blanke et al., 2007). In this regard, in addition to increase investment in water sector, more efforts should also focus on appropriate institutional innovations (e.g., water use association, privatization of irrigation facilities) (Wang et al., 2007, 2010) and policies (e.g., water pricing and water allocation policies through establishing water use rights) (Heaney et al., 2006; Huang et al., 2010).

\section{Acknowledgements}

We thank the two anonymous reviewers for their helpful comments. We acknowledge financial support from the Ministry of Science and Technology (2012CB955700), the National Natural Sciences Foundation of China (71333013, 71161140351, 70925001), International Development Research Center (107093001) and Australian Center for International Agricultural Research (ADP/2010/070).

\section{References}

Blanke, A., Rozelle, S., Lohmar, B., Wang, J., Huang, J., 2007. Water saving technology and saving water in China. Agric. Water Manag. 87 (2), 139-150.

Boelee, E. (Ed.), 2011. Ecosystems for Water and Food Security, Nairobi: United Nations Environment Programme. International Water Management Institute Colombo.

Chen, J., 2007. Rapid urbanization in China: a real challenge to soil protection and food security. CATENA 69 (1), 1-15.

Chen, Z., Chen, G.Q., 2013. Virtual water accounting for the globalized world economy: national water footprint and international virtual water trade. Ecol. Indic $28,142-149$.

Cortignani, R., Severini, S., 2009. Modeling farm-level adoption of deficit irrigation using Positive Mathematical Programming. Agric. Water Manag. 96 (12), 1785-1791.

Deng, X., Huang, J., Han, J., Cai, S., 2012. Impact of urbanization on changes in cultivated land use in china after economic reform. In: The Eighth Annual AsiaPacific Economic Association Conference, Nanyang Technological University, Singapore.

Doorenbos, J., Kassam, A.H., 1979. Yield response to water. FAO Irrigation and Drainage Paper No. 33. FAO, Rome. 
Fang, C., 2009. Issues of resources and environment protection in China's rapid urbanization process and suggestions on countermeasures. Bull. Chin. Acad. Sci. 24 (5), 468-474 (in Chinese).

Friedmann, J., 2006. Four theses in the study of China's urbanization. Int. J. Urban Reg. Res. 30 (2), 440-451.

Graveline, N., Mérel, P., 2014. Intensive and extensive margin adjustments to water scarcity in France's Cereal Belt. Eur. Rev. Agric. Econ., http://dx.doi.org/ 10.1093/erae/jbt039.

Han, M., Guo, S., Chen, H., Ji, X., Li, J., 2014. Local-scale systems input-output analysis of embodied water for the Beijing economy in 2007. Front. Earth Sci. 8 (3) 414-426.

He, L., Horbulyk, T.M., Ali, M.K., Le Roy, D.G., Klein, K.K., 2012. Proportional water sharing vs. seniority-based allocation in the Bow River basin of Southern Alberta. Agric. Water Manag. 104, 21-31.

Heaney, A., Hafi, A., Beare, S., Wang, J., 2006. Water Reallocation in Northern China: Towards More-formal Markets for Water. Agricultural Water Management in China. Australian Government, Australian Center for International Agricultural Research, pp. 130-141.

Helming, J.F., 2005. A Model of Dutch Agriculture based on Positive Mathematical Programming with Regional and Environmental Applications. Wageningen University, Wageningen.

Howitt, R.E., 1995. Positive Mathematical Programming. Am. J. Agric. Econ. 77 (2), 329-342.

Huang, Q., Huang, J., Rozelle, S., Wang, J., 2009. Water management institutiona reform: a representative look at northern China. Agric. Water Manag. 96 (2) 215-225.

Huang, Q., Rozelle, S., Howitt, R.E., Wang, J., Huang, J., 2010. Irrigation water demand and implications for water pricing policy in rural China. Environ. Dev. Econ. 15 (3), 293-319.

Hubacek, K., Guan, D., Barrett, J., Wiedmann, T., 2009. Environmental implication of urbanization and lifestyle change in China: ecological and water footprints. J. Clean. Prod. 17 (14), 1241-1248.

Ji, X., 2011. Ecological accounting and evaluation of urban economy: taking Beijing city as the case. Commun. Nonlinear Sci. Numer. Simul. 16 (3), 1650-1669.

Kendy, E., Wang, J., Molden, D.J., Zheng, C., Liu, C., Steenhuis, T.S., 2007. Can urbanization solve inter-sector water conflicts? Insight from a case study in Hebei Province, North China Plain. Water Policy 9 (Supplement 1 (S1)), 75-93.

Liu, Y., 2004. Research on China's Urbanization Strategy. Economic Science Press, Beijing, pp. 78-85 (in Chinese).

Meinzen-Dick, R., Appasamy, P.P., 2001. Urbanization and Intersectoral Competition for Water. Finding the Source: The Linkages Between Population and Water Woodrow Wilson International Center for Scholars, Washington, DC, pp. 27-51.
Ministry of Water Resources of China, 2006-2010. Water Resources Bulletins of China. China Statistics Press, Beijing (in Chinese)

National Bureau of Statistics of China, 2012. China Statistical Yearbook 2012. China Statistics Press, Beijing.

Röhm, O., Dabbert, S., 2003. Integrating agri-environmental programs into regional production models: an extension of Positive Mathematical Programming. Am. J. Agric. Econ. 85 (1), 254-265.

Satterthwaite, D., McGranahan, G., Tacoli, C., 2010. Urbanization and its implications for food and farming. Philos. Trans. Roy. Soc. B: Biol. Sci. 365 (1554), 2809-2820.

Steduto, P., Hsiao, T.C., Fereres, E., Raes, D., 2012. Crop Yield Response to Water. Food and Agriculture Organization of the United Nations, Rome.

United Nations Development Program, 2013. China Human Development Report 2013: Sustainable and Liveable Cities: Toward Ecological Civilization. Translation and Publishing Corporation, Beijing, China.

United Nations, Department of Economic and Social Affairs, Population Division 2012. World Urbanization Prospects: The 2011 Revision, New York.

Wang, J., Huang, J., Yan, T., 2013. Impacts of climate change on water and agricultural production in ten large river basins in China. J. Integr. Agric. 12 (7), 1267-1278.

Wang, J., Huang, J., Rozelle, S., Huang, Q., Blanke, A., 2007. Agriculture and groundwater development in northern China: trends, institutional responses, and policy options. Water Policy 9 (S1), 61-74.

Wang, J., Huang, J., Rozelle, S., Huang, Q., Zhang, L., 2009a. Understanding the Water Crisis in Northern China: what the government and farmers are doing. Int. J. Water Resour. Dev. 25 (1), 141-158.

Wang, J., Huang, J., Zhang, L., Huang, Q., Rozelle, S., 2010. Water governance and water use efficiency: the five principles of WUA management and performance in China. J. Am. Water Resour. Assoc. 46 (4), 665-685.

Wang, Y., Xiao, H.L., Lu, M.F., 2009b. Analysis of water consumption using a regiona input-output model: model development and application to Zhangye City, Northwestern China. J. Arid Environ. 73 (10), 894-900.

World Bank and the Development Research Center of the State Council, P. R. China, 2014. Urban China: Toward Efficient, Inclusive, and Sustainable Urbanization. World Bank, Washington, DC, http://dx.doi.org/10.1596/978-1-4648-0206-5.

Wu, P. Tan, M. 2012. Challenges for sustainable urbanization: a case study of wate shortage and water environment changes in Shandong. China. Proc. Environ. Sci. 13, 919L 927.

Zhang, L.X., Chen, B., Yang, Z.F., Chen, G.Q., Jiang, M.M., Liu, G.Y., 2009. Comparison of typical mega cities in China using emergy synthesis. Commun. Nonlinear Sci. Numer. Simul. 14 (6), 2827-2836.

Zhang, Z., Yang, H., Shi, M., 2011. Analyses of water footprint of Beijing in an interregional input-output framework. Ecol. Econ. 70 (12), 2494-2502. 